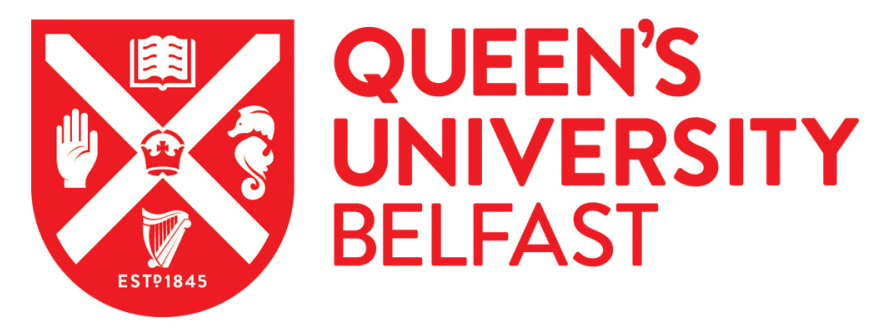

\title{
Synchrotron X-ray diffraction study of the phase transformations in titanium alloys
}

Malinov, S., Sha, W., Guo, Z., Tang, C. C., \& Long, A. (2002). Synchrotron X-ray diffraction study of the phase transformations in titanium alloys. Materials Characterization, 48(4), 279-295. https://doi.org/10.1016/S10445803(02)00286-3

Published in:

Materials Characterization

Queen's University Belfast - Research Portal:

Link to publication record in Queen's University Belfast Research Portal

\section{General rights}

Copyright for the publications made accessible via the Queen's University Belfast Research Portal is retained by the author(s) and / or other copyright owners and it is a condition of accessing these publications that users recognise and abide by the legal requirements associated with these rights.

Take down policy

The Research Portal is Queen's institutional repository that provides access to Queen's research output. Every effort has been made to ensure that content in the Research Portal does not infringe any person's rights, or applicable UK laws. If you discover content in the Research Portal that you believe breaches copyright or violates any law, please contact openaccess@qub.ac.uk. 


\title{
Synchrotron X-ray diffraction study of the phase transformations in titanium alloys
}

\author{
S. Malinov ${ }^{\mathrm{a}}$,W. Sha ${ }^{\mathrm{a}, *}$, Z. Guo ${ }^{\mathrm{a}}$, C.C. Tang ${ }^{\mathrm{b}}$, A.E. Long ${ }^{\mathrm{a}}$ \\ ${ }^{a}$ School of Civil Engineering, The Queens University Belfast, Belfast, BT7 1NN, UK \\ ${ }^{\mathrm{b}}$ Daresbury Laboratory, Warrington, Cheshire, WA4 4AD, UK
}

Received 11 October 2001; accepted 15 March 2002

\begin{abstract}
High-resolution synchrotron X-ray diffraction was used to study the phase transformations in titanium alloys. Three titanium alloys were investigated: $\mathrm{Ti}-6 \mathrm{Al}-4 \mathrm{~V}, \mathrm{Ti}-6 \mathrm{Al}-2 \mathrm{Sn}-4 \mathrm{Zr}-2 \mathrm{Mo}-0.08 \mathrm{Si}$ and $321 \mathrm{~s}$. Both room and high temperature measurements were performed. The room temperature experiments were performed to study the structure of the alloys after different heat treatments, namely as received (AR), furnace cooling (FC), water quenching (WQ) and water quenching followed by ageing. The $\alpha, \alpha^{\prime}, \alpha^{\prime \prime}$ and $\beta$ phases were observed in different combinations depending on the heat treatment conditions and the alloy studied. A multicomponent hexagonal close packed ( $h c p$ ) $\alpha$ phase, with different $c$ and the same $a$ lattice parameters, was detected in Ti-6Al-4Vafter FC. High temperature synchrotron X-ray diffraction was used for 'in situ' study of the transformations on the sample surface at elevated temperatures. The results were used to trace the kinetics of surface oxidation and the concurrent phase transformations taking place under different conditions. The influence of the temperature and oxygen content on the lattice parameters of the $\alpha$ phase was derived and new data obtained on the coefficients of thermal expansion in the different directions of the $h c p$ a phase, for Ti-6Al-4V and Ti-6Al-2Sn-4Zr-2Mo-0.08Si.
\end{abstract}

(C) 2002 Elsevier Science Inc. All rights reserved.

Keywords: Aging; Characterization; Heat treating; Metallography; Microstructure; Phase transformation; X-ray diffraction

\section{Introduction}

In recent decades, a generic class of titaniumbased materials has been developed for range of applications. Titanium and titanium alloys are currently finding increasingly widespread use in many industries due to their combination of very good mechanical properties allied to excellent corrosion and erosion resistance. It is widely known that the mechanical properties of titanium alloys depend essentially on the microstructure, which is formed

\footnotetext{
* Corresponding author. Tel.: +44-2890-274017; fax: +44-2890-663754.

E-mail address: w.sha@qub.ac.uk (W. Sha).
}

during the thermomechanical processing [1a]. It is therefore very important to understand the nature of the phase transformations taking place at different heat treatment conditions. It must be pointed out, however, that 'in situ' studies of the phase transformations have not yet been widely performed for titanium alloys. Most of the research on the microstructure evolution is performed at room temperature on samples quenched after different heat treatments.

Titanium alloys are also appropriate for application at elevated temperatures. The processes and transformations taking place on the alloy surface during high temperature exposure are very important for reliable exploitation. However, there is still a lack of knowledge in this particular area of research. 
The main phases present in titanium alloys are $\alpha$ phase with hexagonal close packed $(h c p)$ structure and $\beta$ phase with body centered cubic $(b c c)$ structure. The type of phases present, grain size and grain shape, morphology and distribution of the fine microstructure determine the properties and therefore the application of titanium alloys. Depending on the ratio of the $\alpha$ and $\beta$ phases, titanium alloys may be classified broadly as $\alpha, \beta$ and $\alpha+\beta[1 \mathrm{a}]$. Within the last category are the subclasses near- $\alpha$ and near- $\beta$, referring to alloys with compositions which place them near to $\alpha /(\alpha+\beta)$ or $(\alpha+\beta) / \beta$ phase boundaries, respectively.

High-resolution X-ray diffraction (HR-XRD) available at a synchrotron radiation source (SRS) is currently a very powerful technique for detailed studies of structure and phase transformation in materials. Such equipment is available at Daresbury Laboratory. The main advantages are the inherent high brightness and the tunable monochromatic beam, which allow the development of a high-resolution instrument. Other special qualities are described elsewhere [2]. The SRS is a high-resolution powder diffraction instrument $[3,4]$. Further developments allow the performance of a variety of experiments by users from a diverse scientific community [5]. With a relatively small instrumental contribution $\left(\Delta 2 \theta \sim 0.006^{\circ}\right)$, it can be used for diffraction line profile analysis of microstructures. As part of the developments, the Daresbury Laboratory has been equipped with an induction furnace (room temperature to $1500{ }^{\circ} \mathrm{C}$ ) for nonambient diffraction studies [6]. These facilities allow 'in situ' studies of different phenomena occurring at elevated temperatures.

There are reports on the potential use of synchrotron-based methods to study different effects in titanium alloys [7-9]. However, there are no references in the literature nor are the authors aware of instances when high temperature HR-XRD has been used to study phase transformations in conventional titanium alloys.

The main aim of this work is to apply room and high temperatures synchrotron radiation HR-XRD measurements to study the phase transformations taking place at different conditions in the most commonly used titanium alloys. This should result in an understanding of the processes at the alloy surfaces during high temperature exposure.

\section{Experimental procedure}

Three popular commercial titanium alloys were used in the present study: Ti-6Al-4V (Ti 6-4), Ti$6 \mathrm{Al}-2 \mathrm{Sn}-4 \mathrm{Zr}-2 \mathrm{Mo}-0.08 \mathrm{Si}$ (Ti 6-2-4-2) and $\beta 21 \mathrm{~s}$. The alloys were provided by Timet UK. The compositions of the alloys used are given in Table 1.
Table 1

Composition in weight percent and heat treatment conditions of the samples used for synchrotron radiation diffraction measurements

\begin{tabular}{|c|c|c|}
\hline Alloy & $\begin{array}{l}\text { Chemical } \\
\text { composition }\end{array}$ & Heat treatments \\
\hline $\mathrm{Ti}-6 \mathrm{Al}-4 \mathrm{~V}$ & $\begin{array}{l}\mathrm{Al}=6.59, \mathrm{~V}=4.1 \\
\mathrm{Fe}=0.18, \mathrm{C}<0.01 \\
\mathrm{H}=0.002, \mathrm{~N}=0.005 \\
\mathrm{O}=0.19\end{array}$ & $\begin{array}{l}\text { As received } \\
\text { Furnace cooled } \\
1100{ }^{\circ} \mathrm{C} \\
\text { Water quenched } \\
1100{ }^{\circ} \mathrm{C}^{\mathrm{a}} \\
\text { Water quenched } \\
850{ }^{\circ} \mathrm{C}^{\mathrm{a}} \\
\text { Water quenched } \\
850{ }^{\circ} \mathrm{C}+ \\
\text { Ageing } \\
600{ }^{\circ} \mathrm{C} / 20 \mathrm{~h}\end{array}$ \\
\hline $\begin{array}{c}\mathrm{Ti}-6 \mathrm{Al}-2 \mathrm{Sn}- \\
4 \mathrm{Zr}-2 \mathrm{Mo}- \\
0.08 \mathrm{Si}\end{array}$ & $\begin{array}{l}\mathrm{Al}=6.13, \mathrm{Sn}=1.93 \\
\mathrm{Zr}=3.97, \mathrm{Mo}=1.95 \\
\mathrm{Si}=0.11, \mathrm{Fe}=0.07 \\
\mathrm{C}<0.01, \mathrm{H}=0.0045 \\
\mathrm{~N}=0.0020, \mathrm{O}=0.065\end{array}$ & $\begin{array}{l}\text { As received } \\
\text { Furnace cooled } \\
1100{ }^{\circ} \mathrm{C} \\
\text { Water quenched } \\
1100{ }^{\circ} \mathrm{C}\end{array}$ \\
\hline Beta21s & $\begin{array}{l}\mathrm{Al}=3.00, \mathrm{Mo}=14.1 \\
\mathrm{Nb}=3.48, \mathrm{Si}=0.14 \\
\mathrm{Fe}=0.32, \mathrm{C}=0.016 \\
\mathrm{~N}=0.024, \mathrm{H}=0.0963 \\
\mathrm{O}=0.15\end{array}$ & $\begin{array}{l}\text { As received } \\
\text { Furnace cooled } \\
900{ }^{\circ} \mathrm{C}^{\mathrm{a}} \\
\text { Water quenched } \\
900{ }^{\circ} \mathrm{C}^{\mathrm{a}}\end{array}$ \\
\hline
\end{tabular}

a Samples for which high temperature measurements were performed.

For each alloy, samples in different heat treatment conditions were studied (see Table 1).

HR-XRD experiments were carried out at the SRS. The detailed features of the diffraction instrument are described elsewhere $[5,10,11]$. The sample dimensions were $20 \times 20 \times 1.5 \mathrm{~mm}$. Measurements were performed both at room temperature and at high temperatures. For all measurements, a wavelength of $0.14 \mathrm{~nm}$ was used. The wavelength was calibrated using high quality silicon powder.

The room temperature measurements were performed mostly in the range $30-70^{\circ}$ in $2 \theta$ and, in some cases, $22-115^{\circ}$ in $2 \theta$ with a step size of $0.01^{\circ}$. In order to minimise the measurement time, the high temperature measurements were performed in two ranges as follow:

$-30-40^{\circ}$ in $2 \theta$ with a step size of $0.01^{\circ}$ and counting time of $1 \mathrm{~s} / \mathrm{step}$ giving a total measurement time of $17 \mathrm{~min}$;

$-40-70^{\circ}$ in $2 \theta$ with a step size of $0.05^{\circ}$ and counting time of $1 \mathrm{~s} /$ step giving a total measurement time of $10 \mathrm{~min}$.

A sample was placed in the furnace chamber, which was then evacuated down to $2 \times 10^{-3}$ Torr in order to prevent chemical reaction of the samples with air. The 


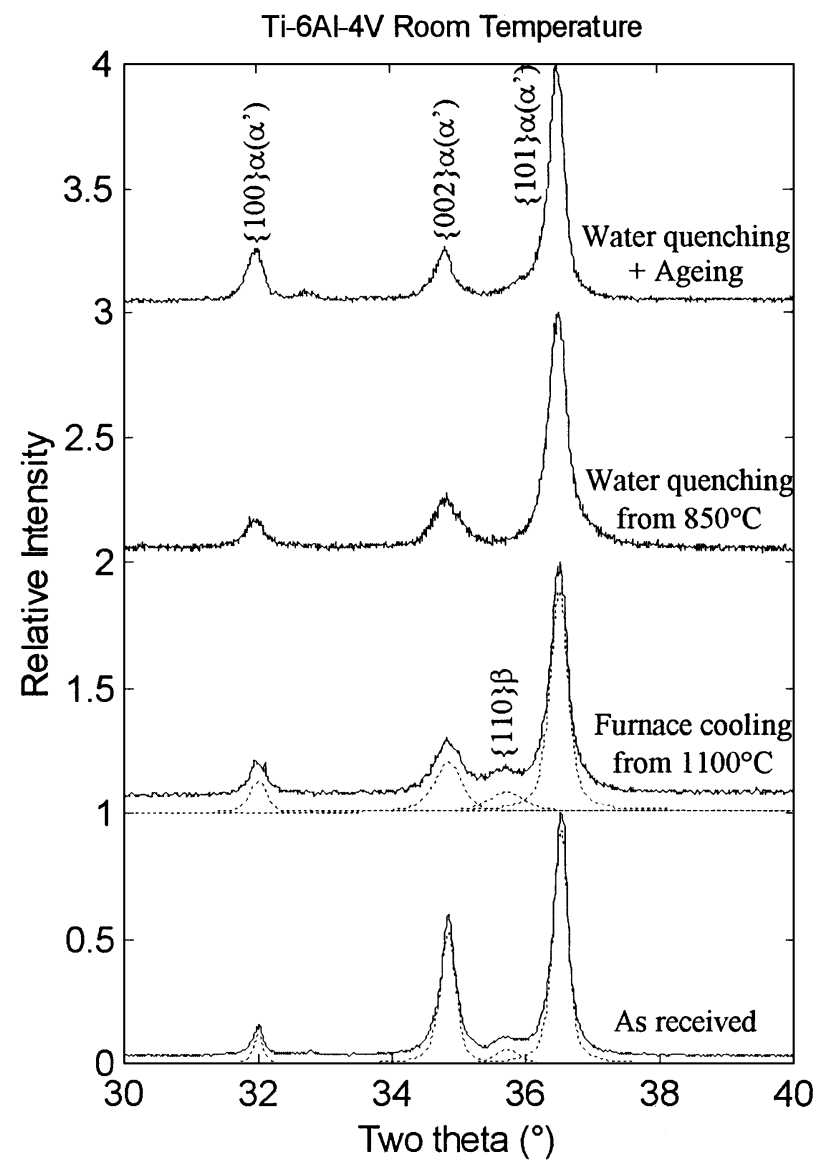

Fig. 1. Diffraction patterns at room temperature and profile fits (dotted lines) in the range $30-40^{\circ} 2 \theta$ for $\mathrm{Ti}-6 \mathrm{Al}-4 \mathrm{~V}$ samples at different heat treatment conditions. The intensities are given relative to the $\{101\} \alpha$ reflection. For clarity, the diffraction patterns are shifted with respect to each other along the vertical axis.

temperature was quickly raised to the set temperature (stability $= \pm 1{ }^{\circ} \mathrm{C}$ ) and the measurements were performed at isothermal conditions. Then the temperature was raised to the next desired temperature and again measurements were performed. As a result of this procedure, a set of diffraction patterns at different temperatures and times was obtained. The process of raising the sample temperature is short, within a few minutes, and the measurements were started immediately after the temperature reached the set values.

The peaks in the diffraction patterns were fitted and the peak parameters were obtained. For the fitting of the profile shape, a symmetric pseudo-Voigt function was used.

The lattice parameters of the hcp $\alpha$ phase for different alloys at different conditions were derived from the fitted diffraction patterns. The reflections $\{100\},\{101\},\{102\}$ and $\{103\}$ were used. The $a$ and $c$ lattice parameters of the hexagonal structure were calculated from the intercept and slope of plots of $1 / d_{h k l}^{2}$ versus $l^{2}$. The accuracy of the determined lattice parameter was $\pm 0.00005 \mathrm{~nm} .{ }^{1}$ The lattice parameters of the $b c c \beta$ phase were derived from reflection $\{200\} \beta$.

Light and scanning electron microscopy as well as microhardness measurements were made on cross sections of the samples to study the microstructure before and after high temperature exposure.

\section{Results and discussion}

\subsection{Synchrotron radiation measurements at room temperature}

The diffraction patterns obtained from the SR measurements at room temperature for $\mathrm{Ti} 6-4, \mathrm{Ti}$

${ }^{1}$ The error in the value of the lattice parameter was calculated based on the assumption that the accuracy in determining the peak positions after fitting was $1 / 5$ of the employed step size in $2 \theta$. 
$6-2-4-2$ and $\beta 21 \mathrm{~s}$ alloys at different heat treatment conditions are presented in Figs. 1-3.

\subsubsection{Ti-6Al-4V alloy}

Five Ti 6-4 samples in different heat treatment conditions were studied:

(i) as received (AR);

(ii) furnace cooling (FC) (with cooling rate of 0.5 ${ }^{\circ} \mathrm{C} / \mathrm{s}$ ) after $\beta$-homogenisation at $1100{ }^{\circ} \mathrm{C}$;

(iii) water quenching (WQ1) after $\beta$-homogenisation at $1100{ }^{\circ} \mathrm{C}$;

(iv) water quenching (WQ2) after homogenisation in $\alpha+\beta$ region at $850{ }^{\circ} \mathrm{C}$;

(v) water quenching after homogenisation in $\alpha+\beta$ region at $850{ }^{\circ} \mathrm{C}$ followed by ageing at $600{ }^{\circ} \mathrm{C}$ for $20 \mathrm{~h}(\mathrm{WQ} 2+\mathrm{AG})$.

This most commonly used titanium alloy is classified as an $\alpha+\beta$ titanium alloy. The phase composition of the Ti 6-4 alloy after different heat treatments was found to be mainly $\alpha$ phase (see Fig. 1). In AR condition, a small amount of $\beta$ phase was observed.
The amount of the $\beta$ phase was calculated from the fitted diffraction patterns using the 'direct comparison method' [12] and found to be $4.8 \pm 1.0 \mathrm{wt} . \%$. In order to avoid error due to preferred orientation, the quantitative analysis was based on the entire diffraction pattern instead of using single reflections. The principle of 'averaging the integral intensities' was applied. All $\alpha$ and $\beta$ reflections observed were used.

There was also a small amount of retained $\beta$ phase after FC from the $\beta$-region (see the small peak at $\approx 35.6^{\circ}$ in $2 \theta$ in Fig. 1). During slow cooling, the diffusional redistribution of the alloying elements leads to enrichment of the $\beta$ phase with $\beta$ stabilizer. As a result, a small amount of $\beta$ phase remains stable at room temperature. A similar observation for the alloy studied has been reported in Ref. [13] for cooling from the $\beta$-region with different cooling rates. The amount of the $\beta$ phase after FC was estimated to be $7.3 \pm 1.5$ wt. $\%$.

An interesting observation was ascertained for the Ti 6-4 sample regarding the reflections at high $2 \theta$ angles. After FC, the reflection $\{103\} \alpha$ apparently

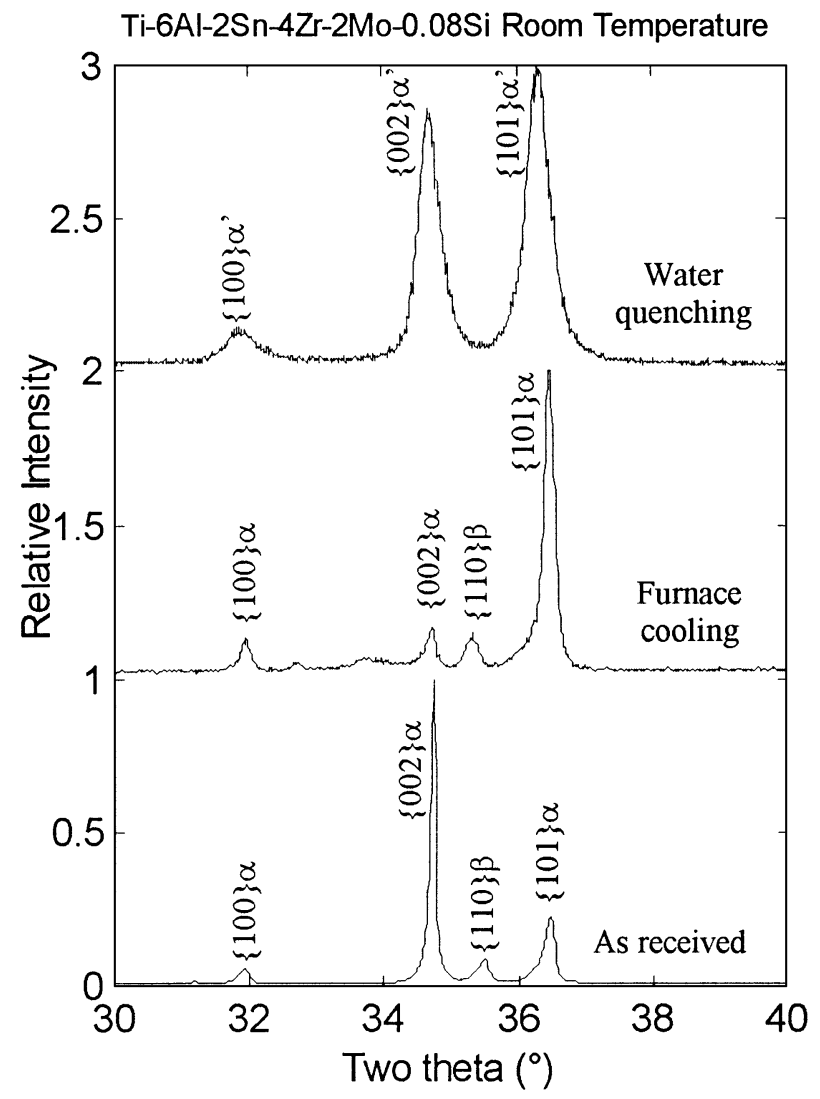

Fig. 2. Diffraction patterns at room temperature in the range $30-40^{\circ} 2 \theta$ for $\mathrm{Ti}-6 \mathrm{Al}-2 \mathrm{Sn}-4 \mathrm{Zr}-2 \mathrm{Mo}-0.08 \mathrm{Si}$ samples at different heat treatment conditions. The intensities are given in relative values. For clarity, the diffraction patterns are shifted with respect to each other along the vertical axis 


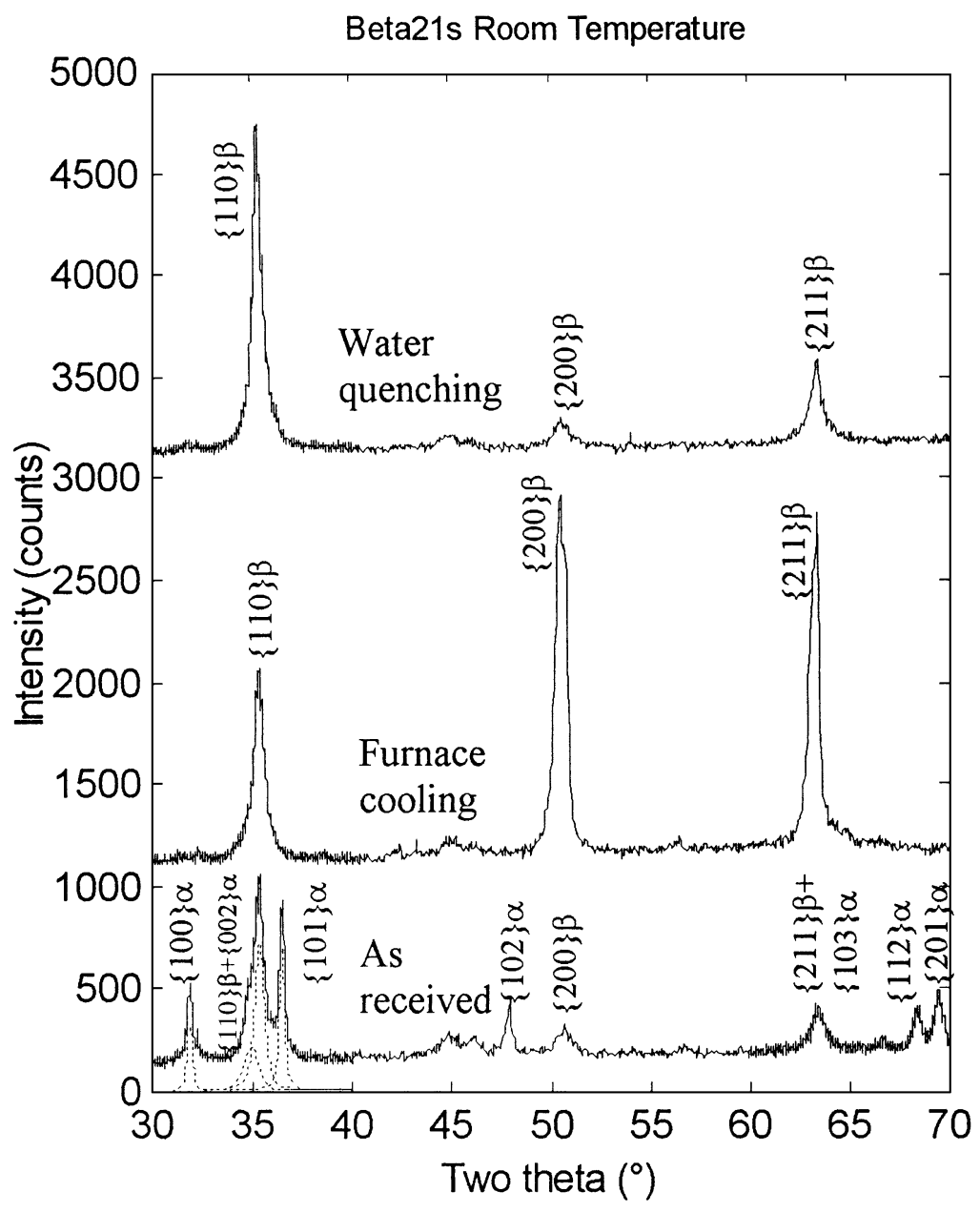

Fig. 3. Diffraction patterns at room temperature and profile fits (dotted lines) in the range $30-70^{\circ} 2 \theta$ for $\beta 21 \mathrm{~s}$ samples at different heat treatment conditions. For clarity, the diffraction patterns are shifted with respect to each other along the vertical axis.

consisted of a number of subpeaks (see Fig. 4(b), FC). This fact was also observed for $\{102\} \alpha$ and $\{112\} \alpha$ reflections, but not for $h k l$ reflections having $l=0$ (see Fig. 4(a)). These observations imply that after slow (furnace) cooling $\alpha$ phases with different $c$ and the same $a$ lattice parameters are formed. The $a$ lattice parameter of the $\alpha$ phase after FC was $0.2938 \mathrm{~nm}$, while the $c$ lattice parameters corresponding to the four subpeaks presented in Fig. 4(b) were 0.4701, 0.4684, 0.4668 and $0.4655 \mathrm{~nm}$ (see Table 2). The above observation can be explained by considering the nature of the $\beta \Rightarrow \alpha$ transformation in titanium alloys. It is well known that, for titanium alloys, the transformation from $\beta$ to $\alpha+\beta$ is of monovariant type. For different temperatures, different amounts of $\alpha$ and $\beta$ phases are in equilibrium and the $\alpha$ phase can be precipitated at different stages (temperatures) during slow continuous cooling. The $\alpha$ phase precipitated at different temperatures has different morphology- finer lamellae are attributed to lower temperatures of transformation [14]. This may result in different levels of the residual stresses for $\alpha$ phase precipitated at different temperatures. In addition, the composition in terms of alloying elements of the $\alpha$ phase precipitated at different temperatures is different. The above two reasons represent the most plausible explanation for the $\alpha$ phase observed with different $c$ lattice parameters.

After WQ from both $\beta$-region $\left(1100{ }^{\circ} \mathrm{C}\right)$ and $\alpha+\beta$ region $\left(850^{\circ} \mathrm{C}\right)$, the structure of the Ti $6-4$ alloy only consisted of $h c p \alpha$ phase. No amounts of $\beta$ phase were observed. This structure is a product of diffusional (small fraction in final structure) and diffusionless (large fraction) transformations $\beta \Rightarrow \alpha\left(\alpha^{\prime}\right)$ upon quenching. The diffusionless transformation occurs at temperatures below $700-750{ }^{\circ} \mathrm{C}$ and results in the formation of the martensite structure $\left(\alpha^{\prime}\right)$. The evidence for the presence of martensite in these cases is 
(a)

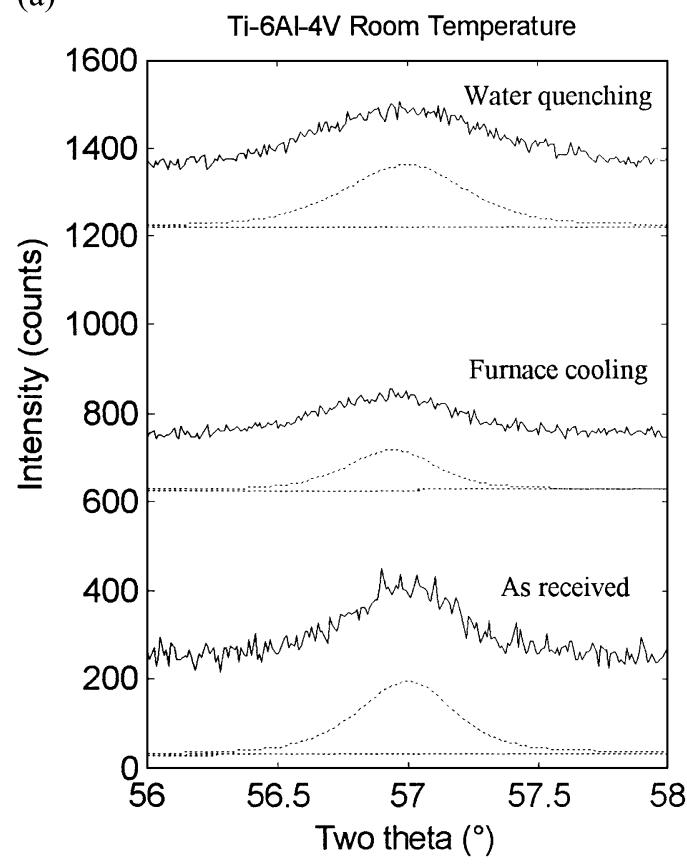

(b)

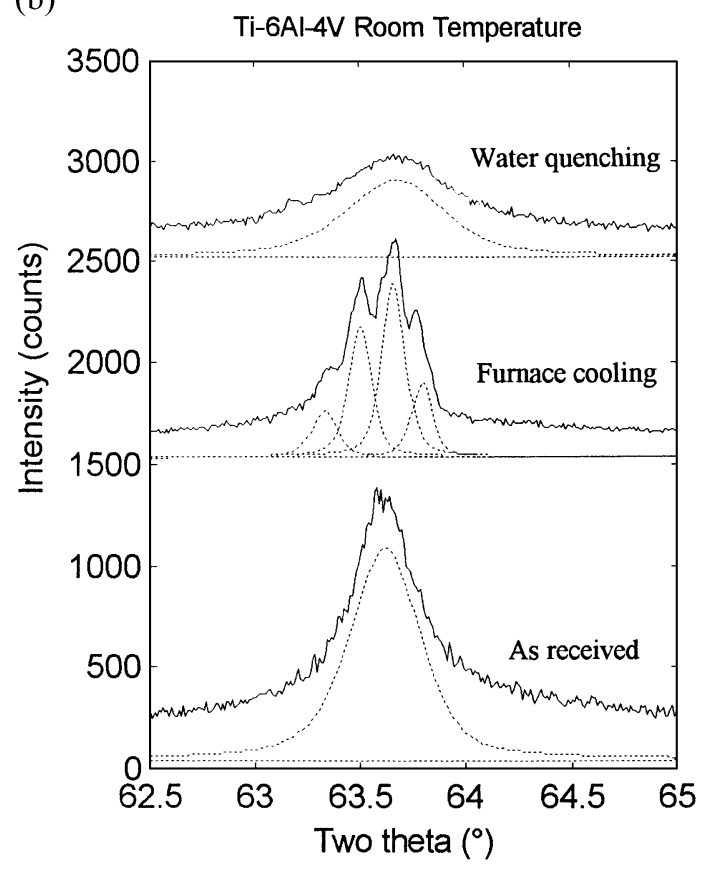

Fig. 4. Reflections and profile fits (dotted lines) of $\{110\} \alpha$ (a) and $\{103\} \alpha$ (b) for Ti-6Al-4V samples at different heat treatment conditions. For clarity, the diffraction patterns are shifted with respect to each other along the vertical axis.

the much wider $\alpha$ reflections (see Fig. 5). The fullwidth half maximum (FWHM) values of all $\alpha$ reflections were nearly twice those in the FC and AR samples. It is suggested that, for Ti 6-4 alloy, quenching from the 750 to $900{ }^{\circ} \mathrm{C}$ temperature range produces an orthorhombic martensite $\left(\alpha^{\prime \prime}\right)$ [1a]. This was not confirmed in the present study. The diffraction patterns of $\mathrm{Ti}$ 6-4 samples quenched from 1100 and $850{ }^{\circ} \mathrm{C}$ were very similar showing the presence of $h c p$ martensite only. Ageing at $600{ }^{\circ} \mathrm{C}$ of the sample quenched from $850{ }^{\circ} \mathrm{C}$ leads to small changes in the diffraction pattern (Fig. 1, top). A shoulder appears on the left side of the $\{101\} \alpha$ reflection. In addition a new reflection is observed at $32.75^{\circ}(d=0.2483 \mathrm{~nm})$. This implies that there is a new phase precipitated from the $\alpha^{\prime}$ phase. It is possible that the orthorhombic martensite $\left(\alpha^{\prime \prime}\right)$ is precipitated upon ageing, but the reflec-

Table 2

Lattice parameters in nanometers at room temperature for titanium alloys after different heat treatments

\begin{tabular}{|c|c|c|c|c|c|c|}
\hline Alloy & Phase & $\begin{array}{l}\text { Lattice } \\
\text { parameter }\end{array}$ & $\begin{array}{l}\text { As } \\
\text { received }\end{array}$ & $\begin{array}{l}\text { Furnace } \\
\text { cooled } \\
\text { from } \beta\end{array}$ & $\begin{array}{l}\text { Water } \\
\text { quenched } \\
\text { from } \beta\end{array}$ & $\begin{array}{l}\text { Water } \\
\text { quenched } \\
\text { from } \alpha+\beta\end{array}$ \\
\hline \multirow[t]{2}{*}{$\mathrm{Ti}-6 \mathrm{Al}-4 \mathrm{~V}$} & $\alpha$ & $a$ & 0.2935 & $\begin{array}{l}0.2938 \\
0.4701\end{array}$ & 0.2935 & 0.2939 \\
\hline & $\beta$ & $c$ & 0.4673 & $\begin{array}{l}0.4684 \\
0.4668 \\
0.4655 \\
0.3228\end{array}$ & 0.4668 & 0.4673 \\
\hline \multirow[t]{2}{*}{$\begin{array}{c}\mathrm{Ti}-6 \mathrm{Al}-2 \mathrm{Sn}-4 \mathrm{Zr}- \\
2 \mathrm{Mo}-0.08 \mathrm{Si}\end{array}$} & $\alpha$ & $a$ & 0.2937 & 0.2942 & 0.2949 & \\
\hline & $\beta$ & $\begin{array}{l}c \\
a\end{array}$ & $\begin{array}{l}0.4687 \\
0.3254\end{array}$ & $\begin{array}{l}0.4698 \\
0.3264\end{array}$ & 0.4690 & \\
\hline$\beta 21 \mathrm{~s}$ & $\alpha$ & $\begin{array}{l}a \\
c \\
a\end{array}$ & $\begin{array}{l}0.2943 \\
0.4686 \\
0.3267\end{array}$ & 0.3272 & 0.3266 & \\
\hline
\end{tabular}




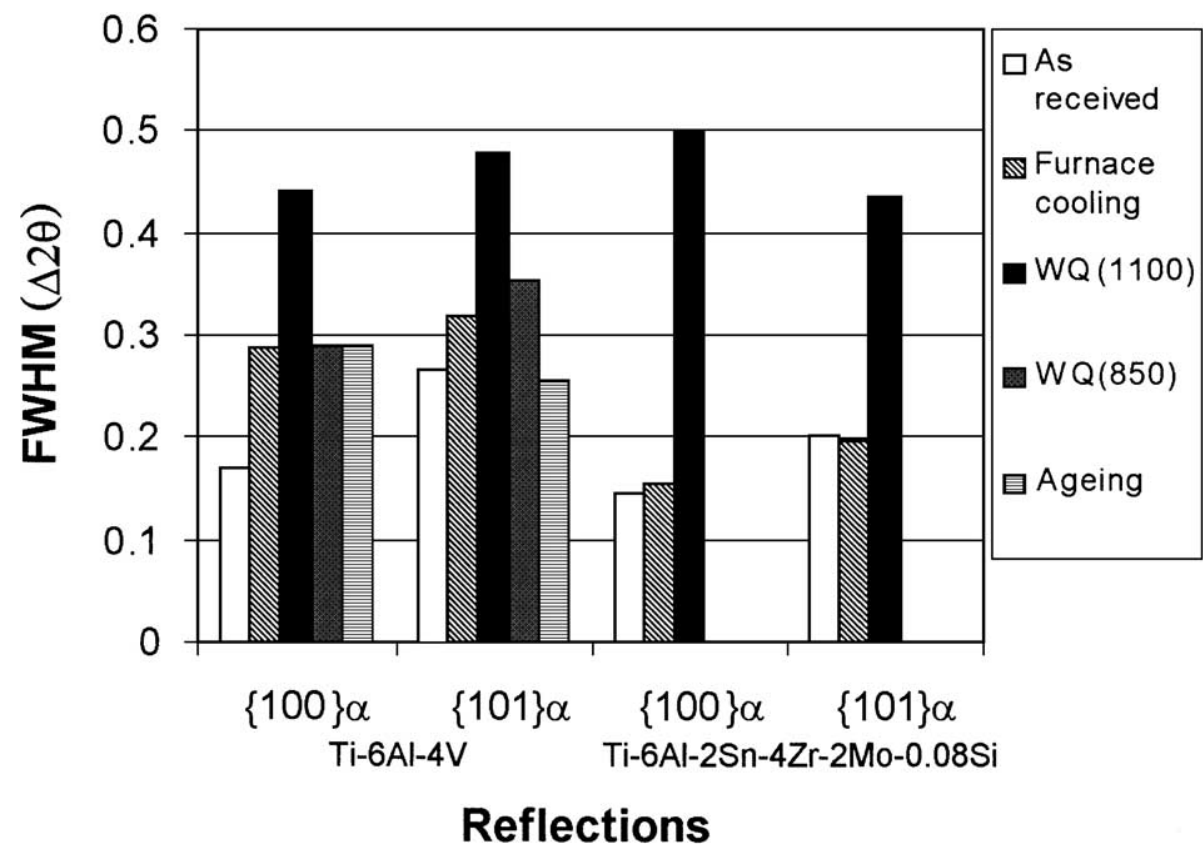

Fig. 5. FWHM for $\alpha$ reflections of $\mathrm{Ti}-6 \mathrm{Al}-4 \mathrm{~V}$ and $\mathrm{Ti}-6 \mathrm{Al}-2 \mathrm{Sn}-4 \mathrm{Zr}-2 \mathrm{Mo}-0.08 \mathrm{Si}$ samples in different heat treatment conditions.

tions were weak and not enough for a clear identification.

\subsection{2. $\mathrm{Ti}-6 \mathrm{Al}-2 \mathrm{Sn}-4 \mathrm{Zr}-2 \mathrm{Mo}-0.08 \mathrm{Si}$ alloy}

This alloy is considered as a near- $\alpha$ titanium alloy [1a]. Three Ti 6-2-4-2 samples in different heat treatment conditions were studied at room temperature, namely $\mathrm{AR}$ and FC and WQ after $\beta$ homogenisation at $1100{ }^{\circ} \mathrm{C}$. The phase composition of all three samples was mainly $\alpha$ phase (see Fig. 2). Small amounts of $\beta$ phase were observed in the $\mathrm{AR}$ and $\mathrm{FC}$ samples, calculated to be $7.5 \pm 1.5 \mathrm{wt} \%$ for both cases. The intensity of the $\{002\} \alpha$ reflection in the AR sample is significantly higher than the intensities of $\{100\} \alpha$ and $\{101\} \alpha$ reflections implying the presence of crystallographic texture. No retained $\beta$ phase was found after WQ. The only phase in the sample after WQ was hcp martensite $\left(\alpha^{\prime}\right)$ phase (see Figs. 2 and 5). The phase constitution of the Ti 6-2-4-2 samples after different heat treatments was very similar to that of $\mathrm{Ti}$ 6-4 samples at the same heat treatment conditions. The lattice parameters of the $\alpha$ phase in both alloys are similar. The lattice parameters of the $\beta$ phase for Ti 6-2-4-2 alloy are appreciably larger compared to these for Ti 6-4 alloy (Table 2). This effect most probably is due to the different composition of the $\beta$ phase at room temperature. In $\mathrm{Ti}-6 \mathrm{Al}-4 \mathrm{~V}$ alloy, the $\beta$ phase is stabilized at room temperature as a result of its enrichment with vanadium. More than 15 wt.\% vanadium (corresponding to Mo-equivalent [Mo] eq of $\sim 11 \mathrm{wt} \%$ ) is necessary to stabilize the $\beta$ phase at room temperature [1a]. In $\mathrm{Ti}-6 \mathrm{Al}-2 \mathrm{Sn}-$ $4 \mathrm{Zr}-2 \mathrm{Mo}-0.08 \mathrm{Si}$ alloy, the $\beta$ phase is stabilized at room temperature as a result of its enrichment with molybdenum. The $\beta$ phase for this alloy has more than 20 wt.\% molybdenum at room temperature [14]. Since the vanadium has lower atomic radius as compared to titanium it causes a decrease in the lattice parameter of the $\beta$ phase in the substitutional solution. Molybdenum, on the contrary, with its higher atomic radius, causes an increase in the lattice parameter.

Considering the schematic pseudobinary phase diagram of titanium alloys [15] the Ti 6-2-4-2 alloy is to the left-side of the Ti 6-4 alloy. This implies that the amount of the residual $\beta$ phase in $\mathrm{Ti}$ $6-4$ should be higher than in $\mathrm{Ti} 6-2-4-2$ alloy. The measurements indicated that the amount of the residual $\beta$ phase in Ti $6-4$ alloy was slightly lower when compared to the Ti 6-2-4-2 alloy. The reason for this discrepancy most probably is due to the difference in the oxygen levels in the two alloys. The amount of oxygen in Ti 6-4 alloy (0.19 wt.\%) was significantly higher than in Ti 6-2-4-2 alloy $(0.065$ wt.\%) (see Table 1). It is well known that the oxygen stabilizes the $\alpha$ phase. The $\beta$ phase is therefore depressed in the Ti 6-4 alloy because of the high oxygen content, and promoted in the Ti 6-2-4-2 alloy because of the low oxygen content. 


\subsection{3. $\beta 21$ s alloy}

The $\beta 21 \mathrm{~s}$ alloy is a metastable $\beta$-titanium alloy [1a]. Three $\beta 21 \mathrm{~s}$ samples in different heat treatment conditions were studied-AR as well as FC and WQ from $900{ }^{\circ} \mathrm{C}$. In the AR sample, mixture of $\alpha+\beta$ crystal structures was observed (see Fig. 3). The amount of the $\alpha$ phase was assessed at 58 wt.\%. The presence of $\alpha$ phase in the AR condition is a result of the heat treatment, i.e., $\beta$ solution treatment followed by ageing. This is a typical condition for a commercial $\beta 21 \mathrm{~s}$ alloy because $\alpha$ precipitation provides strengthening.

Both WQ and FC from $900{ }^{\circ} \mathrm{C}$ produced pure $\beta$ phase microstructure. $\alpha$ phase was not observed after heat treatment. The martensite transus temperature in this alloy is lowered by the alloying elements $(15.75 \%$ [Mo]eq) to temperatures below room temperature. This means that martensite phase $\left(\alpha^{\prime}\right)$ cannot exist in this alloy. As a result retention of the $\beta$ phase at room temperature is permitted if the $\beta \Rightarrow \alpha$ phase transformation is suppressed upon cooling. The results in this study showed that the $\alpha$ phase did not form even after slow FC $\left(0.5{ }^{\circ} \mathrm{C} / \mathrm{s}\right)$. Since a certain amount of $\alpha$ phase should be in equilibrium the reasons for the suspending of the $\alpha$ phase are kinetic.

The lattice parameters of the $\beta$ phase in the $\beta 21 \mathrm{~s}$ alloy were larger than those in $\mathrm{Ti} 6-4$ and $\mathrm{Ti} 6-2-$ 4-2 alloys (see Table 2). Again the reason is in the alloy composition (14.1 wt.\% Mo, 3 wt.\% Al and 3.48 wt.\% Nb). Both molybdenum and niobium have higher atomic radii than titanium and therefore they increase the lattice parameter when substituting titanium atoms in the $b c c \beta$ phase.

\subsection{Synchrotron radiation measurements at elevated temperatures}

Following the experimental procedure, consecutive HR-XRD measurements at different high temperatures were performed. A number of scans at each

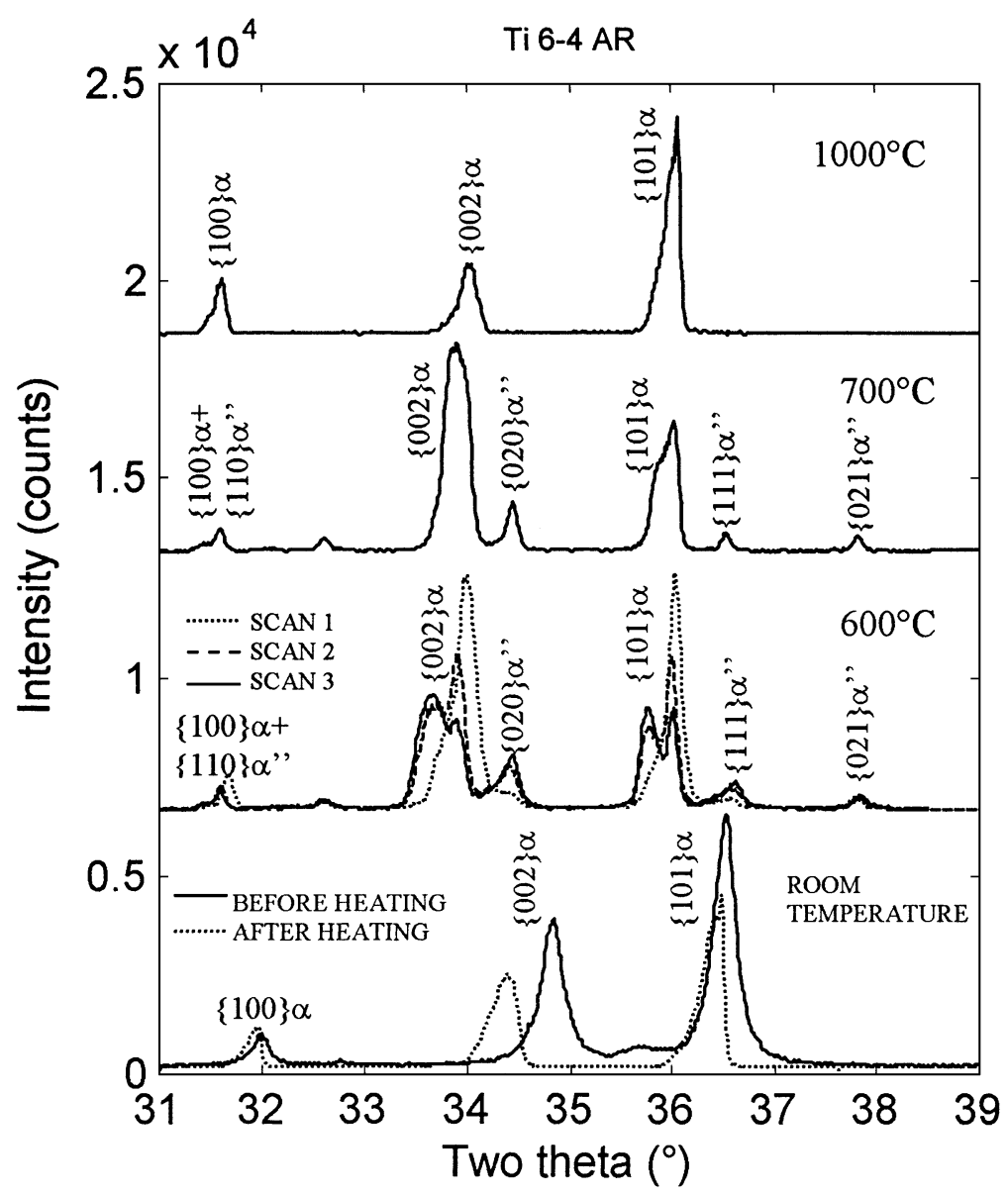

Fig. 6. Diffraction patterns at different temperatures for $\mathrm{Ti}-6 \mathrm{Al}-4 \mathrm{~V}$ alloy. For clarity, the diffraction patterns are shifted with respect to each other along the vertical axis. 
temperature were carried out in order to study the kinetics of possible phase transitions. The high temperature measurements were performed for samples at different heat treatment conditions (see Table 1). The temperatures at which HR-XRD measurements were performed were $600,700,800,900$ and $1000{ }^{\circ} \mathrm{C}$ for Ti 6-4 and Ti 6-2-4-2 alloys, and 600, 750 and $900{ }^{\circ} \mathrm{C}$ for $\beta 21 \mathrm{~s}$ alloy. Afterward, room temperature measurements were performed and the results were analysed. Some of the diffraction patterns obtained from the high temperature measurements of $\mathrm{Ti} \mathrm{6-4,}$ Ti 6-2-4-2 and $\beta 21 \mathrm{~s}$ alloys are shown in Figs. 6-8.

The oxygen content of the samples after high temperature HR-XRD measurements was determined using combustion analysis technique with Leco machine and the results showed increased oxygen content. The oxygen contents were 0.6 wt. $\%, 0.5$ wt.\% and 0.8 wt.\% for Ti $6-4$ (AR), Ti 6-2-4-2
(AR) and $\beta 21 \mathrm{~s}$ (FC) samples respectively. These values were the average oxygen contents of the bulk samples. Apparently, the vacuum level $\left(2 \times 10^{-3}\right.$ Torr) of the furnace chamber was not sufficient to completely prevent oxidation.

It is well known that an increase in the oxygen content raises the $\beta$-transus temperature [1a]. The phase equilibria of the alloys at the temperatures studied were calculated for different oxygen contents (see Fig. 9). The calculations were carried out with Thermo-Calc software and using the Ti-database [16]. The calculations were performed for oxygen contents in the range from 0.0 to $1.4 \mathrm{wt} . \%$. It should be admitted that the Ti-database [16] is validated for oxygen concentrations up to 0.3 wt.\%. Therefore, large errors above this value are possible. Indeed a very significant influence of the oxygen content on the equilibrium contents of $\alpha$ and $\beta$ phases was demon-

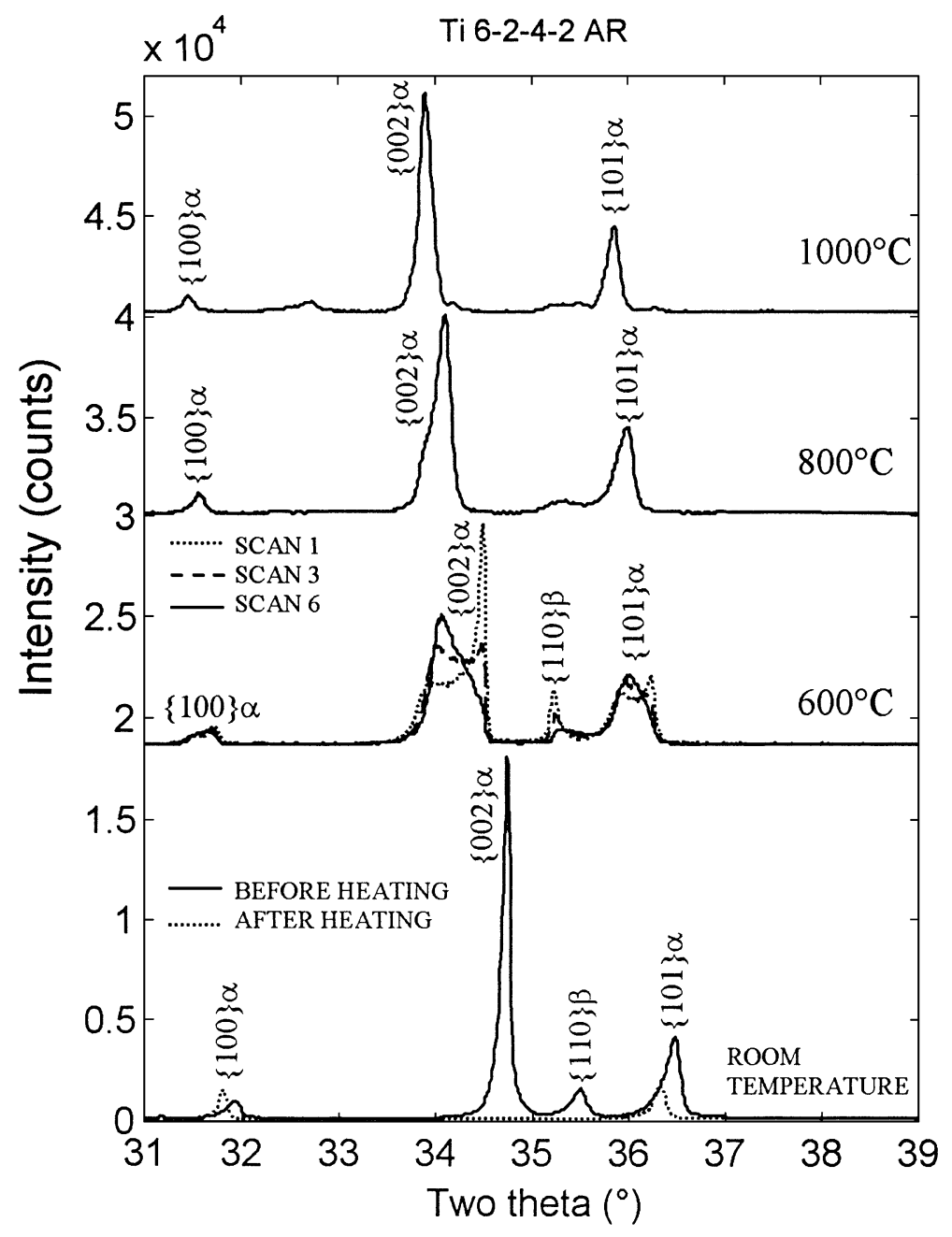

Fig. 7. Diffraction patterns at different temperatures for $\mathrm{Ti}-6 \mathrm{Al}-2 \mathrm{Sn}-4 \mathrm{Zr}-2 \mathrm{Mo}-0.08 \mathrm{Si}$ alloy. For clarity, the diffraction patterns are shifted with respect to each other along the vertical axis. 


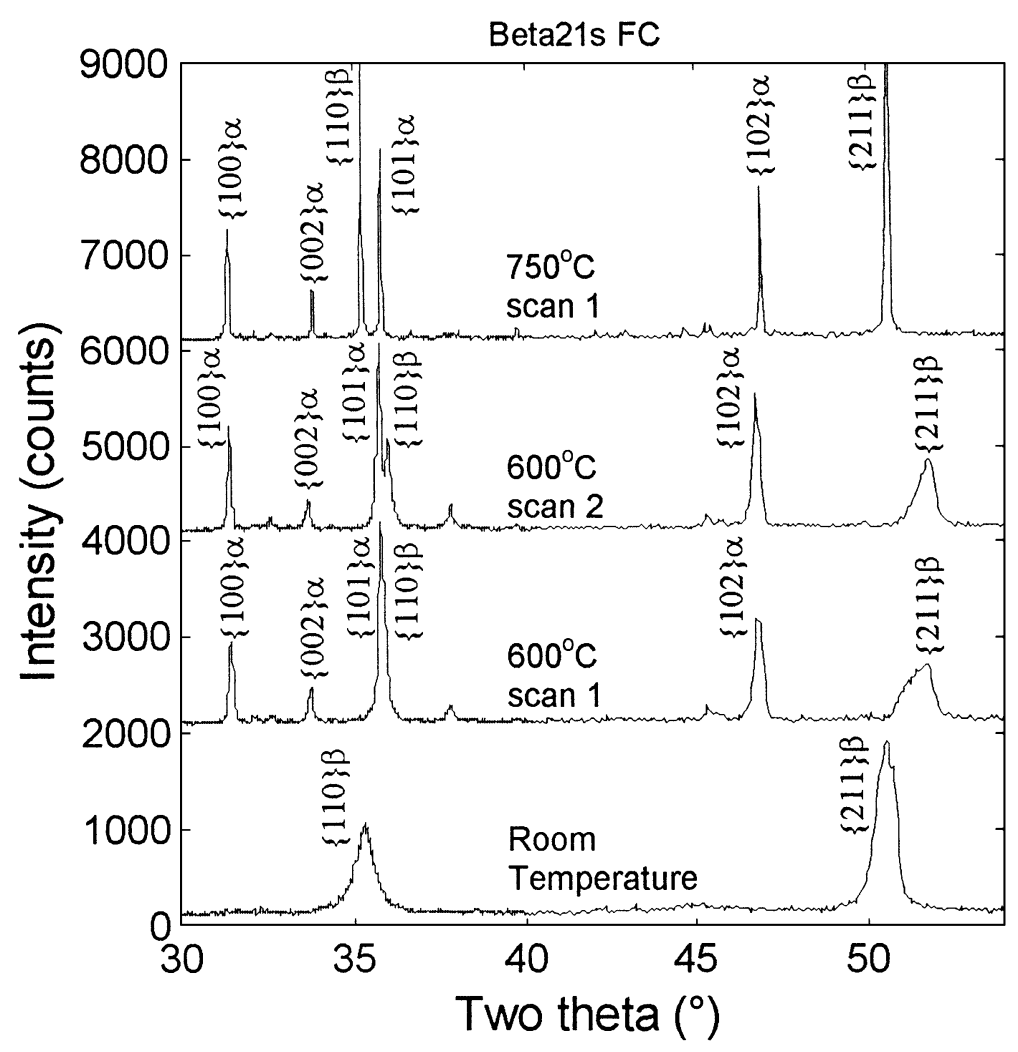

Fig. 8. Diffraction patterns at different temperatures for $\beta 21 \mathrm{~s}$ alloy. For clarity, the diffraction patterns are shifted with respect to each other along the vertical axis.

strated. The increased oxygen content enhances and stabilizes the $\alpha$ phase in respect to the $\beta$ phase.

The microstructure analysis of cross sections of $\mathrm{Ti}$ 6-4 and Ti 6-2-4-2 samples after high temperature HR-XRD measurements showed the presence of a surface oxidized layer (see Fig. 10). The microstructure of the surface layer consisted of coarse $\alpha$ phase lamellae. This was a well-defined layer with an obvious boundary between the layer and the matrix. In addition, some coarse $\alpha$ phase colonies, grown from the surface layer towards the sample core, were observed. The microstructure of the sample core consisted of very fine $(\alpha+\beta)$-plates colonies. The microhardness of the surface layer for Ti 6-4 alloy was $528 \pm 23 \mathrm{HV} 1$ while the microhardness of the matrix was $382 \pm 17$ HV1. The difference in the microhardness of the surface layer and the matrix is mainly due to the difference of the microstructure. The difference in the oxygen level may also have had an influence on the microhardness difference.

The measurements performed on the cross sections using scanning electron microscopy with energy dispersive X-ray and wavelength dispersive $\mathrm{X}$-ray with oxygen detection capability of 0.8 wt.\% did not detect any change in the oxygen counts for the surface layer and the matrix. Hence, the difference in the oxygen levels between the surface layer and the sample core is very small and is undetectable with the technique used.

It should be pointed out that the surface layers have been formed during the entire cycle of high temperature measurements (see Section 2). The surface layer shown in Fig. 10 had a thickness of 145 $160 \mu \mathrm{m}$, and is a result of high temperature exposure as follows: $1.5 \mathrm{~h}$ at $600{ }^{\circ} \mathrm{C}+1 \mathrm{~h}$ at $700{ }^{\circ} \mathrm{C}+0.5 \mathrm{~h}$ at $800{ }^{\circ} \mathrm{C}+0.5 \mathrm{~h}$ at $900{ }^{\circ} \mathrm{C}+0.5 \mathrm{~h}$ at $1000{ }^{\circ} \mathrm{C}$. Hence, the phase transformations observed at high temperature are in conditions of concurrent oxidation. This is taken into account in the analysis and discussion of the results obtained.

Before analysis of the results, it should also be mentioned that the diffraction patterns were obtained from a surface layer the thickness of which is limited by the depth of the X-ray beam penetration. The depth of the X-ray penetration was assessed to be in the range $5-6.5 \mu \mathrm{m}$ for scan in the range $30-40^{\circ}$ in $2 \theta$ and $\sim 12 \mu \mathrm{m}$ at $70^{\circ}$ in $2 \theta$. Hence, the diffraction patterns obtained are related to the phase transformations taking place within surface layers with the abovementioned thickness. 
(a)

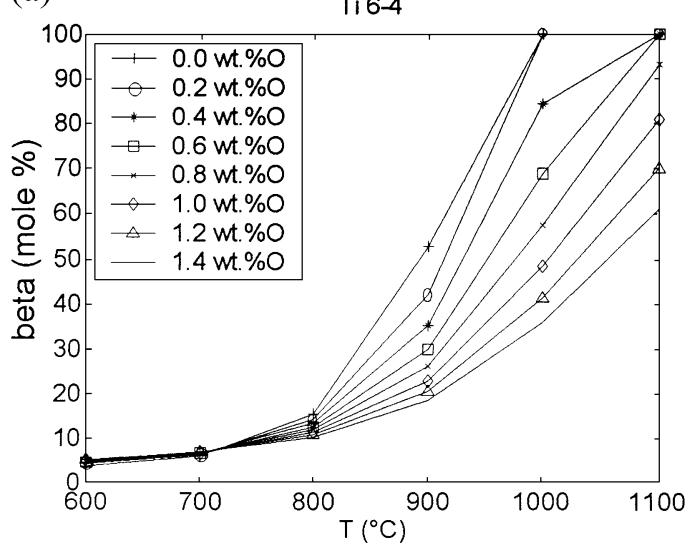

(b)

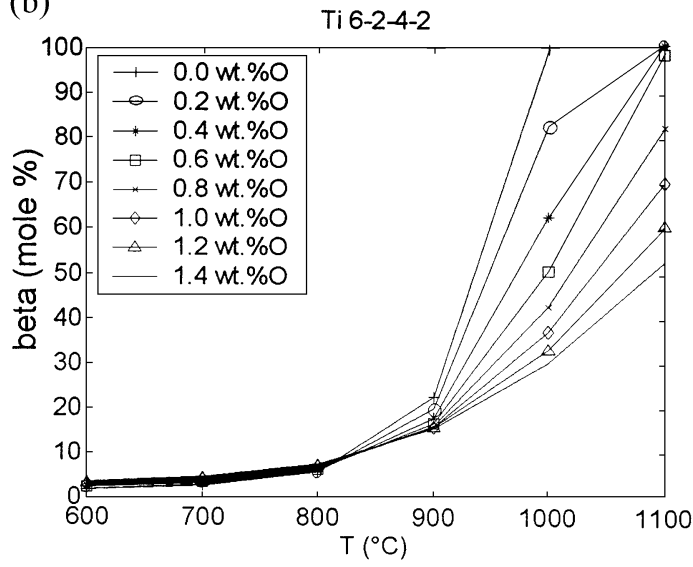

(c)

Beta21s

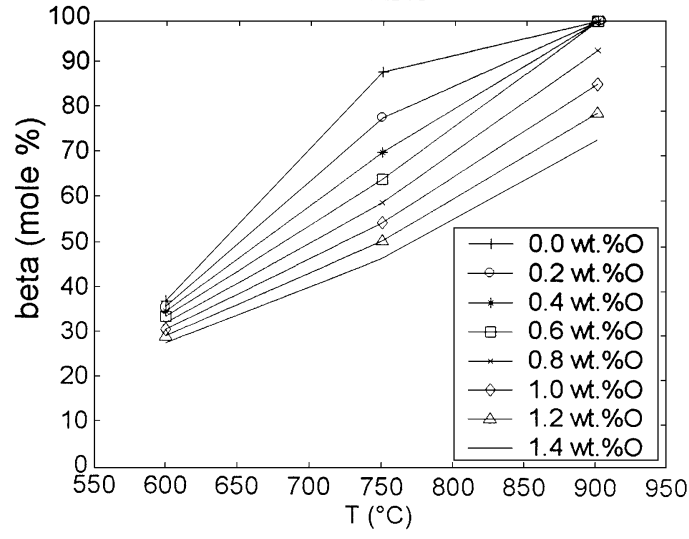

Fig. 9. Calculated equilibrium $\beta$-phase fractions versus temperature for different oxygen levels for Ti-6Al-4V (a), Ti-6 Al$2 \mathrm{Sn}-4 \mathrm{Zr}-2 \mathrm{Mo}-0.08 \mathrm{Si}$ (b) and $\beta 21 \mathrm{~s}$ (c) titanium alloys.

\subsubsection{Ti- $6 \mathrm{Al}-4 \mathrm{~V}$ alloy}

3.2.1.1. Transformations on the sample surface during high temperature exposure. Three Ti 6-4 samples in different heat treatment conditions (see Table 1) were used for high temperature measurements. The results obtained from the three simples were similar. In what follows, the results from the AR sample will be discussed. The microstructure of Ti 6-4 (AR) sample at room temperature, as stated above, was $\alpha$ phase plus a small amount $(\sim 5$ wt.\%) of $\beta$ phase. Fig. 6 shows some of the results from the high temperature HR-XRD measurements. In all diffraction patterns at high temperatures, the reflections corresponding to $h c p$ a phase were mainly observed. The $\beta$ phase was not observed at high temperatures. The reason for this most probably is the increased oxygen content of the sample.

When the sample was heated up to $600{ }^{\circ} \mathrm{C}$ complicated diffraction patterns were recorded (see Figs. 6 and 11a). All reflections were shifted to lower
$2 \theta$ angles as compared to the room temperature reflections due to the effect of thermal expansion. The peaks of the $h c p$ a phase apparently consisted of two ingredients having two separate sets of $h c p$ lattice parameters. Some additional small peaks also were detected. These peaks were not identified as additional titanium oxides, which were different from the oxidized $h c p$ structure.

The diffraction patterns at $600{ }^{\circ} \mathrm{C}$ can be explained with surface oxidation of the sample. The ingredients of the $h c p$ reflections, which are shifted to lower $2 \theta$ angles, belong to the oxidized surface layer. The ingredients of the $h c p$ reflections, which are at higher $2 \theta$ angles, belong to the unoxidized $\alpha$ phase layer underneath. These results imply the apparent existence of a concentration gap for the oxygen content in the $h c p$ structure on the sample surface. The results obtained are in agreement with the observed welldefined sharp boundary between the oxidized layer and the matrix. At this stage, the oxidized surface layer (Fig. 10) has a thickness smaller than the depth 

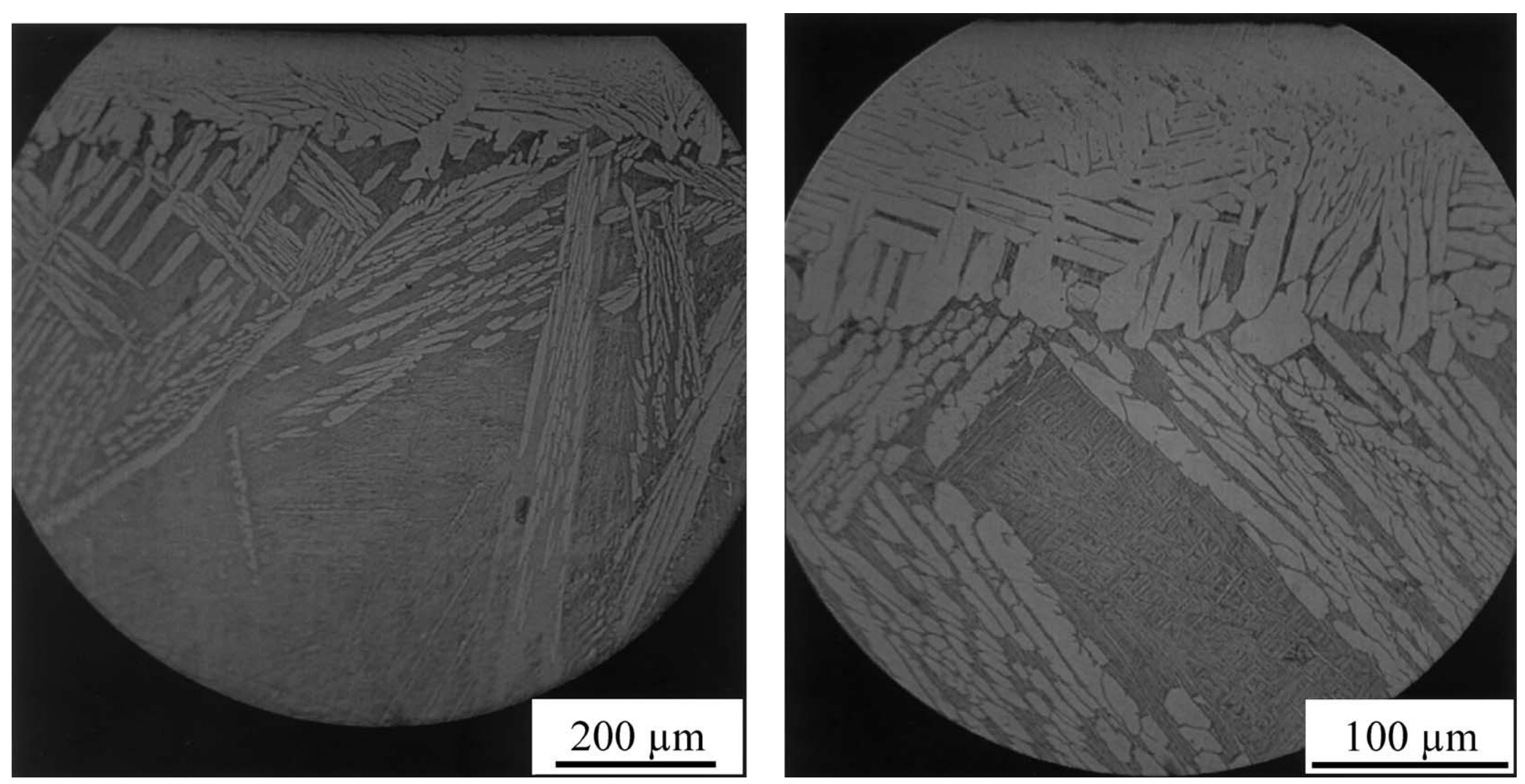

Fig. 10. Microstructure of surface oxidised layer after high temperature HR-XRD measurements of Ti-6Al-4V alloy. 
(a)

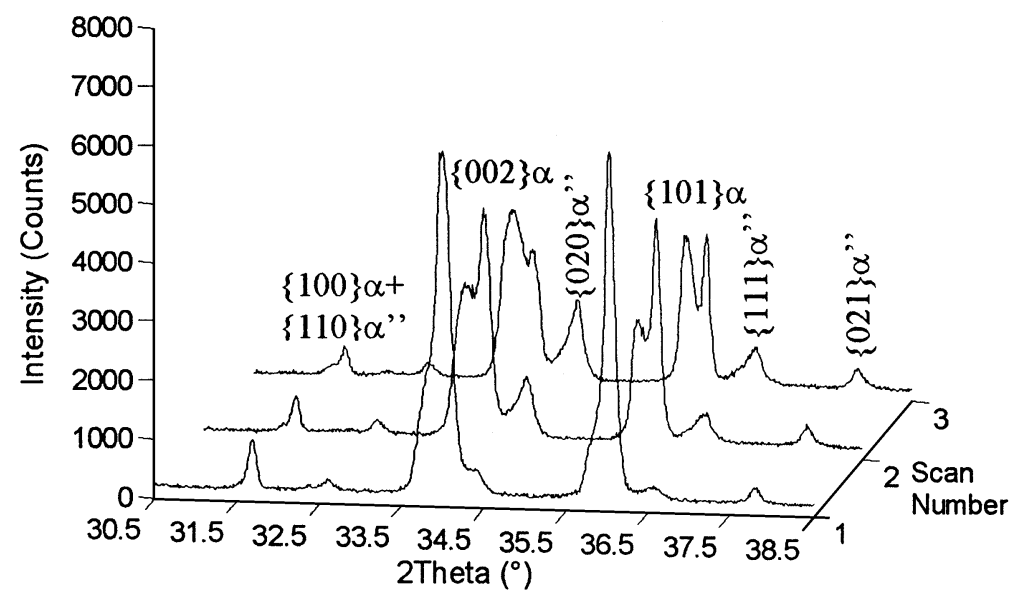

(b)

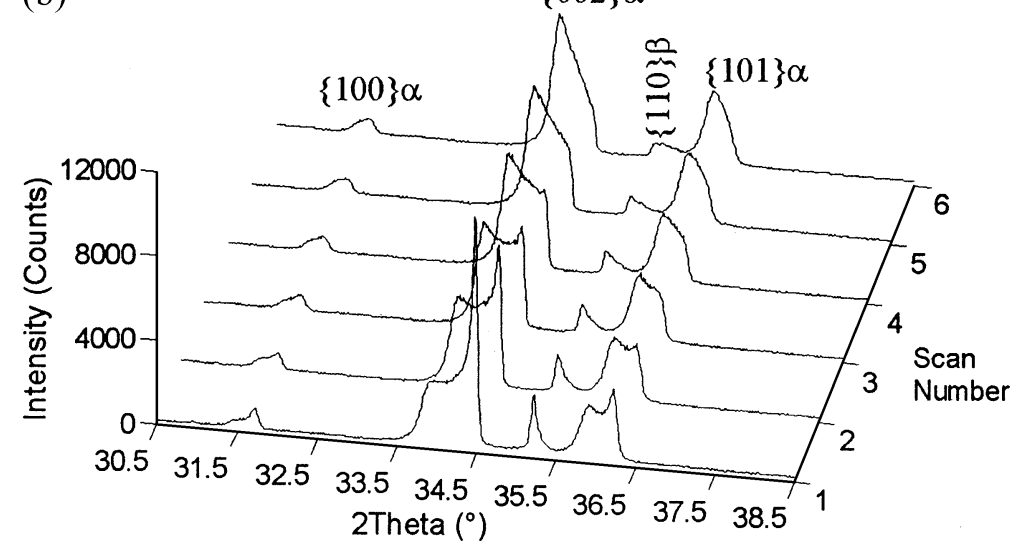

Fig. 11. X-ray diffraction patterns in the range $30.5-38.5^{\circ} 2 \theta$ for $\mathrm{Ti}-6 \mathrm{Al}-4 \mathrm{~V}$ (a) and $\mathrm{Ti}-6 \mathrm{Al}-2 \mathrm{Sn}-4 \mathrm{Zr}-2 \mathrm{Mo}-0.08 \mathrm{Si}(\mathrm{b})$ showing the kinetics of the transformation during isothermal exposure at $600{ }^{\circ} \mathrm{C}$.

of the X-ray penetration. The small additional reflections were identified as belonging to orthorhombic $\alpha^{\prime \prime}$ phase. This phase was observed at temperatures 600 and $700{ }^{\circ} \mathrm{C}$ (see Fig. 6). At higher temperatures (800, 900 and $1000^{\circ} \mathrm{C}$ ), only the main reflections of the $h c p$ $\alpha$ phase were observed indicating that the $\alpha^{\prime \prime}$ phase had disappeared.

With the increasing time at $600{ }^{\circ} \mathrm{C}$, an increase of the integral intensities of the 'low $2 \theta$ angle' (oxidized) with respect to the 'high $2 \theta$ angle' (unoxidized) $h c p$ phase was observed (see Figs. 6 and 11a). A simultaneous increase of the integral intensities of the $\alpha^{\prime \prime}$ reflections was detected. This observation can be explained with oxide layer growth with time and therefore the increase in thickness. However, even in the third scan, there were still reflections from the underneath matrix, which means that the thickness of the surface oxidized layer is still smaller than the depth of X-ray penetrations $(\sim 6 \mu \mathrm{m})$. On the other hand, the increasing intensities of the $\alpha^{\prime \prime}$ reflections indicate that this phase behaves as a stable phase in the temperature range of $600-700{ }^{\circ} \mathrm{C}$.

When the temperature was increased up to 700 ${ }^{\circ} \mathrm{C}$, the diffraction pattern showed single reflections of the $h c p$ phase and reflections of the $\alpha^{\prime \prime}$ phase (see Fig. 6). The peaks belonging to the $\alpha$ phase were not in pairs and were quite broad. The diffraction patterns obtained from the first and the second scans at $700{ }^{\circ} \mathrm{C}$ were identical. These observations imply that the oxide layer has grown to a thickness deeper than the effective penetration depth of the beam. Furthermore, the diffraction pattern is from an inhomogeneous surface oxidized layer with a continuous concentration gradient of oxygen from the sample surface to the core.

A further increase of the temperature up to 800 , 900 and $1000{ }^{\circ} \mathrm{C}$ (Fig. 6) showed the presence of the main reflections of the $h c p \alpha$ phase only. The $\beta$ phase, 
as well as reflections of orthorhombic $\alpha^{\prime \prime}$ phase, were not present. The peaks were sharp implying homogeneity. At these stages, the surface oxidized layer is much thicker. There is still an oxygen gradient in the entire oxidized layer but the diffraction pattern is from the first $6 \mu \mathrm{m}$ of the layer where the oxygen concentration can be regarded as constant.

It should be mentioned that at these temperatures the phase $\alpha \Rightarrow \beta$ transformation should take place. In the inner (unoxidized) part of the sample, this transformation has occurred. The experimental confirmation for this is the observed very fine $\alpha+\beta$ colonies microstructure in the sample core (see Fig. 10). This microstructure is a product of $\beta \Rightarrow \alpha+\beta$ phase transformation, which has taken place upon fast cooling from the final temperature of measurements (1000 ${ }^{\circ} \mathrm{C}$ ) to room temperature. However, the increased oxygen content suppresses the $\alpha \Rightarrow \beta$ transformation on the sample surface upon heating. This results in the formation of a coarse $\alpha$ microstructure on the sample surface during heating and after cooling. Finally, it may also be assumed that at high temperatures some processes of homogenisation in respect to the oxygen may take place. As a result, the difference in the oxygen levels of the surface layers and the matrix become smaller.

\subsubsection{Influence of the temperature and oxygen on} the lattice parameters. The diffraction patterns obtained at different temperatures were displaced in respect to each other along the $2 \theta$ implying difference in the lattice parameters. There are two main reasons, which in this case may have an influence on the lattice parameter of the $\alpha$ phase, namely the oxygen content and the thermal expansion. These two factors have concurrent influence, but they can be distinguished. The influence of the oxygen content can be derived from the difference between the diffraction patterns at room temperature before heating (normal oxygen content) and after heating (increased oxygen content). The influence of the temperature (the thermal expansion) can be derived from the difference between the diffraction patterns at the last high temperature measurement $\left(1000{ }^{\circ} \mathrm{C}\right)$ and the room temperature measurement after cooling (note that the cooling from $1000{ }^{\circ} \mathrm{C}$ after completing the measurement is fast within few seconds resulting in negligible oxidation upon cooling).

The diffraction patterns at room temperature before and after high temperature experiments were not identical. In both cases, the diffraction patterns showed the presence of $\alpha$ phase. Despite the increased oxygen content, titanium oxides were not detected at room temperature after high temperature exposure. However, after heating, the reflections of the $\alpha$ phase were shifted to lower $2 \theta$ angle implying increased lattice parameter(s) (see Fig. 6, bottom). The increase of the lattice parameters of the hcp $\alpha$ phase is due to the increased amount of oxygen. The oxygen is an interstitial element and increases the lattice parameters of the $\alpha$ phase by occupying a fraction of the octahedral interstitial sites. One should note that the shift to lower $2 \theta$ angles is significantly higher for the $\{002\} \alpha$ reflection as compared to the peak shifts of the $\{100\} \alpha$ and $\{101\} \alpha$ reflections (see Fig. 6, bottom). The derived lattice parameters of the $\alpha$ phase were $a=0.2935 \mathrm{~nm}, c=0.4673 \mathrm{~nm}$ for the AR specimen before heating (0.19 wt.\%/0.55 at.\% oxygen) and $a=0.2935 \mathrm{~nm}, c=0.4719 \mathrm{~nm}$ after heating. Hence, the enrichment of the $\alpha$ phase with oxygen results in the increase of the $c$-lattice parameter. The influence of the oxygen on the lattice parameters of the $\alpha$ phase in $\mathrm{Ti} 6-4$ for oxygen concentrations less than 6 at.\% is given in Ref. [1b]. All results for the oxygen influence on the lattice parameters of the pure titanium for oxygen content up to 25 at.\% are summarized in Ref. [17]. The results obtained in this study are in agreement with the previously published results.

The lattice parameters of the $\alpha$ phase at $1000{ }^{\circ} \mathrm{C}$ were calculated to be $a=0.2965 \mathrm{~nm}$ and $c=0.4786$ $\mathrm{nm}$. The coefficients of thermal expansion in the temperature range $20-1000{ }^{\circ} \mathrm{C}$ can be derived by comparing these lattice parameters with the lattice parameters at room temperature after cooling. Values

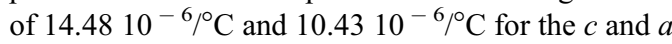
parameters, respectively, were derived. The value for $c$ is higher than the value for $a$. This effect is characteristic of the hcp structure. The derived values are in agreement with the published data for the average linear thermal expansion coefficient for $\mathrm{Ti}$ $6-4$ alloy in the temperature range $0-900{ }^{\circ} \mathrm{C}[1 \mathrm{c}]$ (see Table 3).

\subsection{2. $\mathrm{Ti}-6 \mathrm{Al}-2 \mathrm{Sn}-4 \mathrm{Zr}-2 \mathrm{Mo}-0.08 \mathrm{Si}$ alloy}

Ti 6-4 and Ti 6-2-4-2 alloys have very similar behaviour in respect to the thermodynamics and kinetics of the phase transformations at different conditions [14]. One sample from the Ti 6-2-4-2 alloy (see Table 1) was studied and the results are presented in Fig. 7.

\subsubsection{Transformations on the sample surface} during high temperature exposure. At $600{ }^{\circ} \mathrm{C}$, the peaks of the hcp $\alpha$ phase consisted of two components (see Figs. 7 and 11b) similar to the $\mathrm{Ti} 6-4$ sample, namely one shifted to lower $2 \theta$ angles (belonging to the oxidized surface layer) and one at higher $2 \theta$ angles (belonging to the unoxidized underneath material). The effect of peak separation was more obvious for $\{002\} \alpha$ reflection since, as stated above, the oxygen has a much stronger influence on 
Table 3

Thermal coefficients of linear expansion for $\mathrm{Ti}-6 \mathrm{Al}-4 \mathrm{~V}$ and $\mathrm{Ti}-6 \mathrm{Al}-2 \mathrm{Sn}-4 \mathrm{Zr}-2 \mathrm{Mo}-0.08 \mathrm{Si}$ alloys

\begin{tabular}{|c|c|c|c|c|c|}
\hline \multirow[t]{2}{*}{ Alloy } & \multirow{2}{*}{$\begin{array}{l}\text { Temperature } \\
\text { interval }\left({ }^{\circ} \mathrm{C}\right)\end{array}$} & \multirow[t]{2}{*}{ Ref. } & \multicolumn{3}{|c|}{ Coefficient of thermal expansion, $10^{-6} /{ }^{\circ} \mathrm{C}$} \\
\hline & & & 'c' direction & 'a' direction & Mean \\
\hline \multirow[t]{3}{*}{$\mathrm{Ti}-6 \mathrm{Al}-4 \mathrm{~V}$} & $20-1000$ & This work & 14.48 & 10.43 & \\
\hline & $0-815$ & {$[1 \mathrm{c}]$} & & & 11.0 \\
\hline & $20-540$ & {$[1 \mathrm{c}]$} & & & 9.5 \\
\hline \multirow{4}{*}{$\begin{array}{c}\mathrm{Ti}-6 \mathrm{Al}-2 \mathrm{Sn}- \\
4 \mathrm{Zr}-2 \mathrm{Mo}\end{array}$} & $20-1000$ & This work & 16.8 & 12.1 & \\
\hline & $20-600$ & This work & 15.8 & 11.5 & \\
\hline & $20-540$ & {$[1 \mathrm{~d}]$} & & & 10 \\
\hline & $20-300$ & {$[1 \mathrm{~d}]$} & & & 9.3 \\
\hline
\end{tabular}

the $c$ lattice parameter. Additional reflections from other phases were not observed for this alloy. Some amount of $\beta$ phase was detected.

The increase in time at $600{ }^{\circ} \mathrm{C}$ led to increasing of the intensities of the low $2 \theta$ angles component of the $h c p$ reflections in respect to the high $2 \theta$ angles component and a decrease in the amount of the $\beta$ phase (see Figs. 7 and 11b). A number of consecutive scans were performed in order to study the kinetics of the oxide layer growth (see Fig. 11b). The amounts of the oxidized $\alpha$ phase were assessed from the ratio of the integrated intensity of the low $2 \theta$ angle component (after fitting) and the total intensity of the corresponding reflection. These calculations were performed for scans after different periods of time at $600{ }^{\circ} \mathrm{C}$. The results obtained are plotted in Fig. 12 as a fraction of the oxidized $\alpha$ phase versus square root of the time. The results, in this way plotted, can well be approximated with a straight line which is characteristic of diffusional processes. Since all consecutive scans were at the same conditions the results showing the increase of the amount of the oxidized phase with time actually trace the kinetics of growth of the surface oxidized layer.

At higher temperatures (700, 800, 900 and 1000 ${ }^{\circ} \mathrm{C}$ ), single peaks from $\alpha$ phase were observed. The reflections are from the oxidized surface $\alpha$ phase. The oxide layer has grown to a thickness deeper than the X-ray beam penetration. Very small amounts of $\beta$ phase were still detected. The lower oxygen content in this sample, as compared to the Ti 6-4 sample, is the most plausible reason for the presence of small amounts of $\beta$ phase. The surface oxidized $\alpha$ phase had different lattice parameters at different temperatures due to the thermal expansion.

\subsubsection{Influence of the temperature and oxygen on} the lattice parameters. The reflections at the room temperature measurements were shifted, after heating, to lower $2 \theta$ angles (see Fig. 7, bottom) in a similar way to the Ti 6-4 alloy as a result of increased lattice parameters due to oxidation. The $\{002\} \alpha$ reflection was not observed at room temper- ature after the high temperature exposure. The lattice parameters after heating were $a=0.2947 \mathrm{~nm}$ and $c=0.4727 \mathrm{~nm}$. The influence of the oxygen content on the lattice parameters can be estimated from the comparison between the lattice parameters before heating $(a=0.2937 \mathrm{~nm}$ and $c=0.4687 \mathrm{~nm})$ and after heating. Again, a much stronger influence of the oxygen on the $c$ lattice parameter was observed. Data on the oxygen influence of the lattice parameters for this alloy were not found in the literature.

The lattice parameters were calculated for the different temperatures. At $600{ }^{\circ} \mathrm{C}$, the calculations were performed for both oxidized and unoxidized $\alpha$ phase. The coefficients of thermal expansions in both directions ( $a$ and $c$ ) were derived for the temperature intervals $20-600$ and $20-1000{ }^{\circ} \mathrm{C}$. The calculations for the temperature interval $20-600{ }^{\circ} \mathrm{C}$ were based on the diffraction patterns at room temperature before heating and at $600{ }^{\circ} \mathrm{C}$ (unoxidized). The calculations for the temperature interval $20-1000{ }^{\circ} \mathrm{C}$ were based on the diffraction patterns at room temperature after heating and at $1000{ }^{\circ} \mathrm{C}$. The results are given in Table 3 together with published data [1d] on the mean

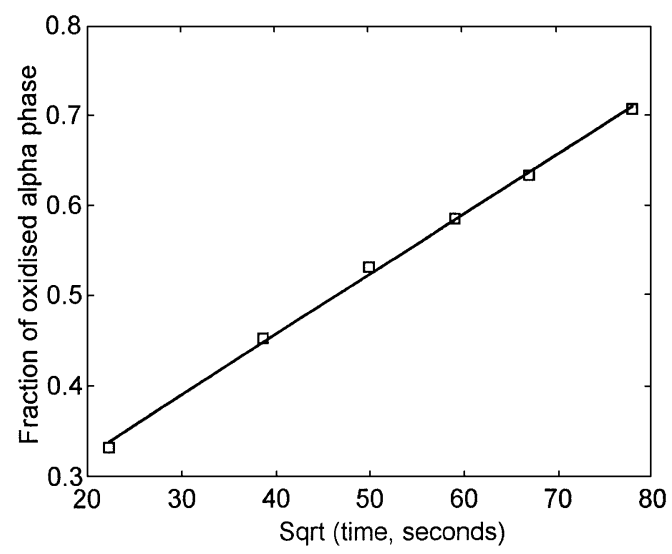

Fig. 12. Amount of oxidised $\alpha$ phase vs. sqrt(time) plot showing the kinetics of surface oxidation of $\mathrm{Ti}-6 \mathrm{Al}-2 \mathrm{Sn}-$ $4 \mathrm{Zr}-2 \mathrm{Mo}-0.08 \mathrm{Si}$ alloy at $600{ }^{\circ} \mathrm{C}$. 
thermal expansion coefficient for Ti 6-2-4-2 alloy at different temperature intervals. The results obtained are in agreement with the data published and extend them to higher temperatures.

\subsection{3. $\beta 21$ s alloy}

Two $\beta 21 \mathrm{~s}$ samples after different heat treatment conditions were studied using high temperature HRXRD (see Table 1). The heat treatment conditions of the samples were WQ and FC after $\beta$ homogenisation. The initial states of both samples were homogeneous $\beta$ phase (see Fig. 3). The results obtained from high temperature HR-XRD study of both samples were very similar. In the following, the results from the FC sample are discussed.

As stated before, the $\beta 21 \mathrm{~s}$ alloy was studied at temperatures 600,750 and $900{ }^{\circ} \mathrm{C}$. Three consecutive scans (see experimental procedure for the scan parameters) were performed at $600{ }^{\circ} \mathrm{C}$ in order to study the kinetics of possible phase transformations. For the higher temperatures $\left(750\right.$ and $\left.900{ }^{\circ} \mathrm{C}\right)$, two consecutive scans were carried out. Some of the diffraction patterns obtained from HR-XRD study of $\beta 21$ alloy at high temperatures are presented in Fig. 8.

Starting with the initial $100 \% \beta$ phase at room temperature, the sample was heated up to $600{ }^{\circ} \mathrm{C}$ and $h c p \alpha$ phase was observed. The reflections of the $\beta$ phase were shifted to higher $2 \theta$ angles. The $\{110\} \beta$ and $\{101\} \alpha$ reflections were overlapped at the first scan (see scan 1 at $600{ }^{\circ} \mathrm{C}$ on Fig. 8). With the increasing time at $600{ }^{\circ} \mathrm{C}$, a further small shift of the $\beta$ reflections to higher $2 \theta$ angles was observed. The $\{110\} \beta$ and $\{101\} \alpha$ reflections were partially separated (see scan 2 at $600{ }^{\circ} \mathrm{C}$ on Fig. 8).

The results obtained indicate that a phase transformation $\beta \Rightarrow \alpha$ takes place on the sample surface when the sample is heated from room temperature to $600{ }^{\circ} \mathrm{C}$. Two concurrent reasons for this transformation are suggested: (i) precipitation of the $\alpha$ phase during the high temperature measurements (ageing); (ii) the increased oxygen content on the sample surface, which enhances and stabilizes the $h c p$ a phase in respect to the $b c c \beta$ phase. In spite of the thermal expansion the reflections of the $\beta$ phase were shifted to higher $2 \theta$ angles. This shows a decreased lattice parameter of the $\beta$ phase at $600{ }^{\circ} \mathrm{C}$ as compared to room temperature. There was some evidence for an increase of the lattice parameters of the $\alpha$ phase during the isothermal exposure at $600{ }^{\circ} \mathrm{C}$. These changes can be associated with the diffusional redistribution of the alloying elements between the $\alpha$ and the $\beta$ phases during $\beta \Rightarrow \alpha+\beta$ phase transformation, namely decreasing of the amounts of molybdenum and niobium in the $\beta$ phase and increasing in the $\alpha$ phase.

Increasing of the temperature up to $750{ }^{\circ} \mathrm{C}$ and $900{ }^{\circ} \mathrm{C}$ results in: (i) increasing the amount of the $\beta$ phase and decreasing of the $\alpha$ phase and (ii) a significant shift of the reflections of the $\beta$ phase to lower $2 \theta$ angles (see Fig. 8 top). The diffraction patterns from the second scans at 750 and $900{ }^{\circ} \mathrm{C}$ were identical to the first scans. This shows that no phase transformations took place during isothermal holding and the phase equilibrium had been achieved. All reflections become sharp implying phase homogenisation.

Apparently, a reverse transformation $\alpha \Rightarrow \beta$ took place when the temperature was raised from 600 to $750{ }^{\circ} \mathrm{C}$. This observation is in agreement with what is expected from the phase diagram ( $\beta$ phase is the high temperature phase). The phase transformations taking place on the sample surface during high temperature HR-XRD can be expressed as:

$\beta\left(20{ }^{\circ} \mathrm{C}\right) \Rightarrow \alpha+\beta\left(600{ }^{\circ} \mathrm{C}\right) \Rightarrow \alpha \downarrow+\beta \uparrow\left(750{ }^{\circ} \mathrm{C}\right)$

The diffraction pattern at $900{ }^{\circ} \mathrm{C}$ still showed the presence of $\alpha$ phase. The most plausible reason for the presence of the $\alpha$ phase is the increased oxygen content, which increases the $\beta$ transus temperature.

The lattice parameters of both $\alpha$ and $\beta$ phases are affected by the above transformations. However, in this case, it is difficult to distinguish between the contribution from the different factors (temperature, oxygen content, alloying elements redistribution).

Finally, it should be mentioned that the experimentally observed and the calculated amounts (Fig. 9) of $\alpha$ and $\beta$ phases at different temperatures were in agreement for the $\beta 21 \mathrm{~s}$ alloy. However, for Ti $6-4$ and Ti 6-2-4-2 alloys, the calculated amounts of $\beta$ phase were much higher than those experimentally observed. A possible reason for this discrepancy is that the oxygen level of the samples was significantly higher than the usual for titanium alloys due to the oxidation. The calculations of the phase equilibria, based on the titanium database, are not accurate for such high oxygen contents. In spite of this, the calculation can be used to examine the trend of phase equilibrium with varying oxygen levels.

\section{Summary and conclusions}

Room temperature HR-XRD experiments were performed using a SRS to study the structure of $\mathrm{Ti}-6 \mathrm{Al}-4 \mathrm{~V}, \mathrm{Ti}-6 \mathrm{Al}-2 \mathrm{Sn}-4 \mathrm{Zr}-2 \mathrm{Mo}-0.08 \mathrm{Si}$ and $\beta 21$ s titanium alloys after different heat treatments. The $\alpha, \alpha^{\prime}$ and $\beta$ phases were observed in different combinations depending on the heat treatment conditions and the alloy studied. The results are consistent with what is expected from the theory of the phase transformations in titanium alloys. The lattice parameters of $\alpha$ and $\beta$ phases were obtained after 
different heat treatment conditions for the alloys studied. A multicomponent $\alpha$ phase with different $c$ and the same $a$ lattice parameters was detected in $\mathrm{Ti}-$ $6 \mathrm{Al}-4 \mathrm{~V}$ after FC.

High temperature HR-XRD experiments were used for an 'in situ' study of the transformations in the titanium alloys surface at elevated temperatures. The results obtained are used to:

-trace the kinetics of surface oxidation and the concurrent phase transformations taking place at different conditions for the alloys studied;

-derive the coefficients of thermal expansion in $a$ and $c$ directions of the $h c p$ a phase for Ti-6Al-4V and $\mathrm{Ti}-6 \mathrm{Al}-2 \mathrm{Sn}-4 \mathrm{Zr}-2 \mathrm{Mo}-0.08 \mathrm{Si}$ alloys at temperatures up to $1000{ }^{\circ} \mathrm{C}$;

-derive the influence of oxygen content on the lattice parameters of the $\alpha$ phase for $\mathrm{Ti}-6 \mathrm{Al}-4 \mathrm{~V}$ and $\mathrm{Ti}-$ $6 \mathrm{Al}-2 \mathrm{Sn}-4 \mathrm{Zr}-2 \mathrm{Mo}-0.08 \mathrm{Si}$ alloys.

The results obtained may have a significant practical importance since they have revealed the transformations and processes on the surface of titanium alloys during high temperature exposure.

\section{Acknowledgements}

The authors are grateful to the UK Engineering and Physical Sciences Research Council for the provision of SRS beam time. The authors also appreciate the assistance of Dr. A.F. Wilson from Timet UK in supplying the alloys and providing the chemical analysis and Mr. Trevor Rathbone of the XRD group at Daresbury Laboratory for his excellent technical support in setting up the furnace.

\section{References}

[1] (a) Boyer R, Welsch G, Collings EW, editors. Materials properties handbook: titanium alloys: ASM International. Materials Park, OH; 1994. p. 3-121;

(b) Boyer R, Welsch G, Collings EW, editors. Materials properties handbook: titanium alloys: ASM International. Materials Park, OH; 1994. p. 490;

(c) Boyer R, Welsch G, Collings EW, editors. Materials properties handbook: titanium alloys: ASM International. Materials Park, OH; 1994. p. 516;

(d) Boyer R, Welsch G, Collings EW, editors. Materials properties handbook: titanium alloys: ASM International. Materials Park, OH; 1994. p. 347.

[2] Gerson AR, Halfpenny PJ, Pizzini S, Ristic R, Roberts $\mathrm{KJ}$, Sheen DB, et al. Application of synchrotron Xradiation to problems in materials science. In: Lifshin
E, editor. X-ray characterization of materials. Weinheim, Germany: Wiley-VCH; 1999. p. 105-69.

[3] Cernik RJ, Murray PK, Pattison P, Fitch AN. A 2-circle powder diffractometer for synchrotron radiation with a closed-loop encoder feedback-system. J Appl Crystallogr 1990;23:286-91.

[4] Collins SP, Cernik RJ, Pattison P, Bell ATM, Fitch AN. A 2-circle powder diffractometer for synchrotron radiation on station 2.3 at the SRS. Rev Sci Instrum 1992; 63(1):1013-4.

[5] MacLean EJ, Millington HFF, Neild AA, Tang CC. A versatile diffraction instrument on station 2.3 of the Daresbury Laboratory. Mater Sci Forum 2000;321324:212-4.

[6] Tang CC, Bushnell-Wye G, Cernik RJ. New high- and low-temperature apparatus for synchrotron polycrystalline X-ray diffraction. J Synchrotron Radiat 1998;5: 929-31.

[7] Esaka F, Furuya K, Shimada H, Imamura M, Matsubayashi N, Sato T, et al. Depth profiling of surface oxidized TiAlN film by synchrotron radiation excited X-ray photoelectron spectroscopy. Surf Sci 1997;377 (1-3): 197-200.

[8] Kulkov SN, Mironov YuP. In-situ investigations of the martensitic transformation in TiNi by synchrotron radiation. J Eng Mater - T ASME 1999;121(1):56-60.

[9] Berberich F, Matz W, Richter E, Schell N, Kreissig U, Moeller W. Structural mechanisms of the mechanical degradation of $\mathrm{Ti}-\mathrm{Al}-\mathrm{V}$ alloys: in situ study during annealing. Surf Coat Tech 2000;128:450-4.

[10] Tang CC, Collins SP, Murphy BM, Telling ND, Wogelius RA, Teat SJ. High resolution reflectivity diffractometer on station 2.3 (Daresbury Laboratory). Rev Sci Instrum 1998;69(3):1224-9.

[11] Tang CC, MacLean EJ, Telling ND. Reflectivity and diffraction study of $\mathrm{Co} / \mathrm{Cu}$ multilayer using synchrotron X-rays. J Magn Magn Mater 1999;198-199: $653-5$.

[12] Cullity BD. Elements of X-ray diffraction. Reading (Mass)-London: Addison-Wesley; 1978. p. 411-3.

[13] Malinov S, Guo Z, Sha W, Wilson A. Differential Scanning Calorimetry Study and Computer Modelling of $\beta \Rightarrow \alpha$ Phase Transformation in Ti-6Al-4V Alloy. Metall Mater Trans A 2001;32:879-87.

[14] Malinov S, Markovsky P, Sha W, Guo Z. Resistivity study and computer modelling of the isothermal transformation kinetics of $\mathrm{Ti}-6 \mathrm{Al}-4 \mathrm{~V}$ and $\mathrm{Ti}-6 \mathrm{Al}-2 \mathrm{Sn}-$ 4Zr-2Mo-0.08Si alloys. J Alloy Compd 2001;314: $181-92$.

[15] Nishimura T, Mizoguchi T, Iton Y. Titanium materials for cryogenic services. Kobe Steel Engineering Reports 1984;34(3):63-6.

[16] Saunders N. Modelling of phase equilibria in Ti-alloys. Proc. of the Eight World Conference on Titanium: Titanium '95: Science and Technology, Birmingham, UK (October 22-26, 1995).

[17] Murray JL, editor. Phase diagrams of binary titanium alloys. Materials Park, OH: ASM International; 1987. 